\section{Four Functions in Higher Education}

\section{Claudio de Moura Castro and Daniel C. Levy}

Claudio de Moura Castro is President of the Advisory Board of the Facultade Pitagoras in Brazil and was formerly on the staff of the IntrerAmerican Develoment Bank in Washignton, D.C. E-mail: <claudioc@pitagoras.com.br>. Daniel C. Levy is distinguished professor in the School of Education, State University of New York at Albany. Address: Education Bldg., SUNY-Albany, Albany, NY 12222. E-mail: $<$ dlevy@uamail.albany.edus.

A nalysts generally accept that higher education in most of the world is increasingly differentiated. "The university" can mean many different things, and higher education-or "postsecondary" education or "tertiary" education-increasingly goes beyond what is found at universities. However, much analysis still ignores or underplays differentiation, even though the latter is now rarely openly disputed. The differentiation considered is usually that occurring across institutions, with much too little attention paid to differentiation of functions both across and within institutions.

This differentiation of functions was introduced for the Latin American context in our winter 2001 IHE article and in our book, Myth, Reality, and Reform (Inter-American Development Bank/Johns Hopkins University, 2000). In this article, the idea is to define four different functions and explore what particular requirements they have for fulfillment. Ideally, this tentative typology would help set the stage for researchers and policymakers to consider the utility of the functions for higher education in various parts of the world.

\section{Academic Leadership}

Academic leadership is typically the most prestigious function within academia. But it also occurs quite rarelyeven in the developed world - if the situation is defined by what is done rather than what is claimed. The function involves what scholars usually identify with quality—highly prepared faculty; sophisticated original research published in rigorously reviewed, internationally recognized outlets; graduate education; and selective undergraduate education.

Fulfillment of this function requires ample resources. Research, graduate education, and overall academic quality are costly in both human and physical resources. Academic leadership also usually requires substantial autonomy. In an age in which demands for accountability run rampant, it may seem outmoded to defend the idea that some higher education needs to be lavished with resources and left free from most forms of responsiveness to government or the marketplace. Intellectual activity requires protection. This is not to argue against all controls. It is to emphasize that most appropriate controls are either internal, based on vigorous peer review, or operate in a broad international sphere.

But the tandem need is to identify true academic leadership from among the many pretenders. Otherwise, precious resources are dissipated, and autonomy becomes an unwarranted defense against needed accountability. Too many international higher education policy papers for the developing world offer general system prescriptions that commit a twin error: true academic leadership is denied the chance to survive and grow because its needs are not met, while the great bulk of higher education is treated incorrectly as if it conformed, or should conform, to the academic leadership function.

\section{Professional Development}

This function refers mostly to the preparation of students for specific job markets requiring advanced, extensive formal education. The classic professions like law are joined today by fields like computer science. In many fields, pertinent research, often applied, exists alongside training.

Like the academic leadership function, the professional development function is less common than claimed, and it is too often the proclaimed model for parts of higher education that are not well suited to it. In many countries outside the United States, students enter professional faculties with specific curricula. However, many graduates do not wind up finding jobs that correspond directly to their studies. This often leads to charges of underemployment and of failure.

\section{Academic leadership is typically the most prestigious function within academia.}

Professional higher education should not greatly mimic (whether by choice or coercive rules) standards and policies devised with academic leadership in mind. For example, rather than assuming that full-time professors are better, consideration must be given to blending full-timers with competent professionals who teach individual courses. Similarly, the marketplace is often a better guide to policy and judge of performance than are academically idealized peer review or accreditation systems.

\section{Technological Training and Development}

The technological function is newer, either previously nonexistent or found more commonly at a lower educational level or in on-the-job training. In addition to some applied research, this function is mostly about preparation, often short term, for direct insertion into the job market. 
Here the need is paramount for strong ties to the job market in matters like curriculum development, choice of professors, and evaluation of outcomes. Rapid responsiveness is crucial and should not be hampered by governance and rules more appropriate to other functions. It is also important that technical education not be simply poor-quality professional education. In general, this form of higher education needs to be accorded greater respect and serve as one of the two main types of growing mass higher education.

Rapid responsiveness is crucial and should not be hampered by governance and rules more appropriate to other functions.

\section{General Higher Education}

The other major type of mass higher education is general higher education. Outside the United States, this is often the least recognized function even where it exists de facto. It is usually set up as professional education, but students wind up working in jobs other than those directly in the studied subject matter. Thus, the education is "quasi-professional" and appears to be a failure. It also looks like failure where it lays claim to academic leadership.

Yet general higher education by design instead of by default needs to be pursued and valued. It is probably the form through which most students in large higher education systems can develop analytical skills in reading, writing, and thinking that will be useful in a variety of possible jobsand in broader roles for citizens. Where employment does not correspond to rigid plans of study, curriculum and pedagogy should be redesigned. It is for general higher education that accreditation systems may be most suitable. General higher education offers possibilities for distance education and other alternatives to traditional higher education.

\section{Conclusion}

Although the typology presented here is of course tentative and subject to improvement, it appears promising on two fronts. One is its assistance in identifying and explaining the actual and potential differentiation in higher education. The other is its contribution to the debate over policy-from finance, to governance, to quality controls-by promoting an appreciation of the differences appropriate to different forms of higher education. Neither conceptually nor in terms of policy does one size fit all.

\section{Association of African Universities Charts Goals for 21st Century}

\section{Beth Elise Whitaker}

Beth Elise Whitaker is program associate for Africa, Association Liaison Office for University Cooperation in Development. Address: 1307 New York Ave. NW, Suite 500, Washington, DC 20005, USA.

$\mathrm{T}$ he Association of African Universities (AAU) held its 10th general conference in Nairobi, Kenya, February 5-9, 2001. There were more than 250 participants, including vice chancellors, rectors, and senior academics from 163 member universities and representatives of donor agencies and nongovernmental organizations. The international higher education community was also represented, with participants from associations in the United States, Canada, France, the Netherlands, and Germany. The conference was designed to determine general AAU policies and adopt core priorities for the next four years. Areas of focus included leadership and management, quality of training and research, information and communications technology, and women in African tertiary institutions.

The central theme that emerged from the conference was that African higher education institutions must become more responsive to local development needs. They have fulfilled their postindependence role of training a cadre of civil servants and are now expected to prepare students to participate in a changing global economy. In his keynote address, Professor Ahmadou Lamine Ndiaye, former rector of the Université Gaston Berger in Senegal, argued that higher education's mission of community service is too often forgotten and that universities have a moral obligation to help ameliorate society's problems. Their particular role in national development, according to Ndiaye, should be the application of research findings-especially in science and technology - to immediate problems on the ground.

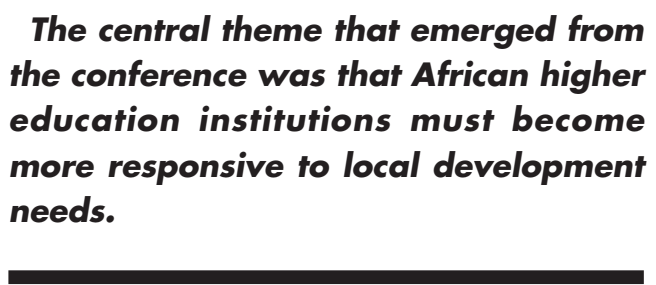

An important aspect of making university education more relevant is the formation of partnerships with private colleges and universities, businesses, and civil society organizations. By tailoring curricula and training programs 